\title{
A CONCEPÇÃO DE ESTUDANTES UNIVERSITÁRIOS ACERCA DA VERGONHA: UM ESTUDO NO CAMPO DA PSICOLOGIA MORAL
}

\author{
Mayara Gama de Lima \\ Universidade Federal do Espírito Santo \\ Heloisa Moulin de Alencar \\ Universidade Federal do Espírito Santo
}

\begin{abstract}
Resumo
A presente pesquisa teve como objetivo investigar o juízo moral de estudantes universitários acerca da vergonha. $O$ instrumento utilizado foi uma entrevista com roteiro semiestruturado, baseada no método clínico proposto por Piaget, contendo questões relativas à concepção de vergonha e ao juízo moral deste sentimento. Os dados revelam que o juízo de valor moral da vergonha envolve conteúdos que a equivalem a um controle externo e a um controle interno, sendo encontradas com maior frequência as categorias juízo e/ou olhares alheios e autojuízo, respectivamente. Espera-se, assim, contribuir com a reflexão sobre a relação entre a vergonha e o universo moral de estudantes universitários, e com o estudo da vergonha e da afetividade na psicologia moral.
\end{abstract}

Palavras chave: Moralidade; vergonha; estudantes universitários.

\section{CONCEPTION OF COLLEGE STUDENTS ABOUT SHAME: A STUDY OF MORAL PSYCHOLOGY}

\begin{abstract}
This study aimed to investigate the moral judgment of college students about the shame. The instrument used was a semi-structured interview based on the clinical method proposed by Piaget, containing questions regarding the design of shame and the moral judgment of this feeling. The data reveal that the judgment of moral value of shame involves content that is equivalent to both an external and internal controls, being the judgment and/or other people's looks and self-judgment, respectively, the more frequently cited categories. We expect to contribute to the study of the moral concerns of college students and to the study of the sense of shame and affectivity in the moral psychology.
\end{abstract}

Keywords: morality; shame; college students.

\section{EL DISEÑO DE ESTUDIANTES UNIVERSITARIOS SOBRE LA VERGÜENZA: UN ESTUDIO EN EL CAMPO DE LA PSICOLOGÍA MORAL}

\begin{abstract}
Resumen
Este estudio tuvo como objetivo investigar el juicio moral de los estudiantes universitarios acerca de la vergüenza. El instrumento utilizado fue una entrevista con preguntas semiestructuradas con base en el método clínico propuesto por Piaget, con preguntas relativas a con el diseño de la vergüenza y el juicio moral de este sentimiento. Así que la vergüenza es igual a la vez un control interno y externo, y aparece como una sensación importante para la moral. Se espera contribuir al estudio del universo moral de los estudiantes universitarios y el estudio del sentido de la vergüenza y de la afectividad en la psicología de la moralidad.
\end{abstract}

Palabras clave: la moralidad; la vergüenza; estudiante universitario. 


\section{INTRODUÇÃO}

O presente artigo teve como objetivo investigar e descrever o juízo moral de estudantes universitários acerca da vergonha. Assume-se, assim como La Taille (2007), que a vergonha se caracteriza como um desconforto psíquico proveniente de dois tipos de situação: a exposição e o juízo negativo. De tal modo que o sujeito pode sentir vergonha pelo simples fato de estar exposto ao olhar alheio ou por julgar negativamente a si mesmo (La Taille, 2007).

Para Harkot-De-La-Taille (1999) o simples fato de ser olhado já coloca o indivíduo em um lugar de objeto para o outro, em uma relação assimétrica, em um lugar de inferioridade. Para esta autora, a vergonha se estabelece no encontro de duas configurações: a inferioridade e a exposição, "seja esta uma exposição real ou virtual a outras pessoas, ou interiorizada, como exposição à própria consciência" (p.30). Portanto, na vergonha, o lugar do outro é o de juiz, é o olhar do outro que, inicialmente, instaura a vergonha, sendo que posteriormente este juízo será interiorizado e se configurará como um autojuízo negativo (Araújo, 2001; Harkot-De-La-Taille, 1999; La Taille, 2002a, 2002b). Algumas pesquisas empíricas têm demonstrado esta associação da vergonha à exposição (Leeming \& Boyle, 2013; Schimith, 2013), e a preocupação com o juízo de terceiros sobre suas ações (Tangney \& Miller, 1996).

Compreende-se, desse modo, que a vergonha não pode ser traduzida como equivalendo a um controle externo, ou decorrente exclusivamente do juízo alheio, visto que para que a vergonha se instaure é necessário que o indivíduo assuma para si ou compartilhe desse juízo alheio. Logo, a vergonha equivale a um controle interno também, uma vez que necessita de uma avaliação negativa que o sujeito realiza sobre o seu Eu. La Taille (2002a, 2002b) ressalta que as representações de si estão, na sua gênese, vinculadas aos juízos alheios, porém tal vínculo não pressupõe uma total dependência desses juízos. Portanto, o juízo negativo de outrem apenas resulta em vergonha se o envergonhado assumir esse juízo para si, logo, pressupõe um autojuízo negativo.

A vergonha se associa com uma avaliação negativa do self, ou seja, ela incide sobre o "eu", sobre o conjunto de representações com valor positivo que o sujeito tem de si mesmo (Tognetta \& La Taille, 2008). Logo, faz parte do grupo das emoções e/ou sentimentos morais e autoconscientes, termos empregados na literatura para definir vergonha, orgulho, constrangimento e culpa (Anolli, 2003; Anolli \& Pascucci, 2005; Costa, 2008; Laskoski, Natividade, \& Hutz, 2013; La Taille, 2006; Santos, 2009; Tangney, Stuewing, \& Mashek, 2007; Tangney \& Tracy, 2012). São definidos como autoconscientes por causa do papel importante que desempenham na moralidade (Santos, 2009): como a representação no self (Anolli, 2003); a legitimação das regras e objetivos sociais (Santos, 2009); e a autoavaliação sobre o próprio eu ou sobre seu comportamento, de forma que 
seja possível confronta-lo com os padrões, regras e objetivos socialmente estabelecidos (Laskoski et al., 2013).

No caso da culpa, da vergonha e do embaraço, estas são emoções que mais do que outras, são sensíveis à violação de normas e estão ligadas a uma condição de dívida em relação aos outros, à perda da autoestima e à necessidade de reparar essa perda (Tangney \& Tracy, 2012). Psicólogos e leigos podem ter dificuldade de diferenciar esses três tipos de experiências afetivas (Tangney \& Miller, 1996), por isso o uso desses termos pode ser impreciso. Portanto, faz-se necessário esclarecer cada um deles.

Na Psicologia, muitas vezes o estudo da vergonha e da culpa tem sido desenvolvido de forma atrelada (Costa, 2008; Orth, Robins, \& Soto, 2010; Stoeber, Harris, \& Moon, 2007; Tangney \& Miller, 1996; Tracy \& Robins, 2006). No entanto é importante ressaltar que apesar de muitas vezes culpa e vergonha serem vividas pelos sujeitos de forma associada, possuem natureza distinta e não devem ser confundidas (Araújo, 2001; La Taille, 2002b). Diferentemente da vergonha, a culpa incide sobre uma ação e suas consequências (La Taille, 2006). Assim compreende-se que "sente-se culpa do que se fez, não do que se é. [...] com a vergonha é diferente: sente-se vergonha do que se é." (La Taille, 2006, p. 134, grifos do autor).

Outro sentimento que muito tem sido confundido com a vergonha é o embaraço. Embora sejam empregados como sinônimos, são construtos diferentes. La Taille (2002a, 2002b) destaca que, no português, os termos vergonha e embaraço são empregados como sinônimos. Ressalta o que há de comum entre esses. Dentre as características comuns aos dois, encontram-se as expressões corporais e o rubor nas faces (Darwin, 1872/1981; Pitt-Rivers, 1965). Entretanto, são atribuídas definições diferentes para cada um de acordo com seus antecedentes (Gouveia, Singelis, Guerra, Santos, \& Vasconcelos, 2005; Gouveia et al., 2006; Sabini, Garvey, \& Hall, 2001; Tangney \& Miller, 1996). De forma geral, o embaraço é desencadeado por situações de confusão "física e de controle corporal (tropeçar em algo), cognitiva (esquecer algo importante), manutenção de privacidade (ter seus sentimentos expostos) e interações sociais desastrosas" (Gouveia et al., 2005, p.331).

Retornando à vergonha, este sentimento demanda que o sujeito tenha consciência de si e realize um autojuízo negativo. Segundo Harkot-De-La-Taille (1999) uma pessoa experimenta a vergonha quando se julga desconexa à "boa imagem" que atribui a si ou que pretende corresponder, de tal forma que, quando o sujeito não mantém uma coerência entre as atitudes e a "boa imagem", pode surgir a vergonha. Dessa forma, "trata-se do sentimento de perda de valor pessoal" (La Taille, 2009, p. 14). O que o sujeito elege como "boas imagens" pode estar associada a diversos conteúdos, logo, o mesmo vale para vergonha, que pode estar associada a conteúdos morais, amorais e imorais. (La Taille, 2001, 2006). Entende-se por moral o conjunto de deveres e regras a 
se cumprir, ou seja, a reposta a pergunta "como devo agir" (La Taille, 2006). Quando os valores morais ocupam um lugar central nas representações de si, aumenta-se a chance de pensar e agir moralmente, bem como de sentir vergonha, caso pratique uma ação imoral (La Taille, 2002a). Essa capacidade de sentir vergonha moral corresponde a um conceito moral clássico, a honra (La Taille, 2007).

Além da culpa e do embaraço, a vergonha também aparece associada ao conceito de humilhação. O que há em comum entre as duas últimas é o fato de o sujeito sentir-se inferiorizado (La Taille, 2002b). Entretanto, na vergonha compartilha-se a imagem negativa imposta, enquanto na humilhação esta imagem pode não ser aceita (La Taille, 2002b). Muitas vezes, a vergonha pode ser resultado de uma situação de humilhação, ou pode surgir associada a esta em uma situação em que há um ataque à "boa imagem" do sujeito (Alencar \& La Taille, 2007; Harkot-De-La-Taille, 1999).

A vergonha, portanto, não é um sentimento exclusivamente moral e pode se relacionar a diversos tipos de conteúdo (La Taille, 2007). Harkot-De-La-Taille (1999) lista cinco tipos de situações na qual a vergonha pode correr: a) ao estar em evidência; b) ao expor sua condição; c) ao revelar sua impotência; d) ao revelar um fracasso; e) ao expor uma falta moral.

A primeira situação refere-se à vergonha de exposição. Ou seja, ao se sentir exposta, a pessoa experimenta a vergonha (Harkot-de-La-Taille, 1999; La Taille, 2002a, 2002b), por exemplo, quando se percebe em evidência em um local cheio de pessoas. A segunda situação faz menção à vergonha de condição, na qual a pessoa sente vergonha de sua origem, sua situação social, econômica etc., ou seja, uma avaliação negativa feita pelo sujeito da condição em que julga ocupar (Alencar \& La Taille, 2007), como a situação de pobreza, deficiência ou limitação, estar empregado (a), ser negro (a) ou índio (a) etc. A terceira situação é a vergonha de fracasso. Refere-se a situações de fracassos em diversos tipos de projetos empreendidos (Alencar \& La Taille, 2007; La Taille, 2002b; Tangney \& Miller, 1996). Por exemplo, as situações em que se fracassa em uma prova ou um exame importante. Outro conteúdo envolve situações de vergonha por impotência. Ou seja, a pessoa sente vergonha pelas circunstâncias às quais foi submetida e que julga que seja impossível reagir e/ou ocorrer uma ação reparadora (Alencar \& La Taille, 2007; Harkot-de-La-Taille, 1999). São situações de privação de afeto, ou episódios de tortura, "espancamento, estupro, sequestro e assassinato de um familiar, preconceito de um grupo sociocultural, assalto à mão armada, corrupção etc." (Alencar, 2003, p.49). O quinto conteúdo relaciona-se à vergonha de contágio. Ou seja, a vergonha é desencadeada por uma ação de outra pessoa, ou por se julgar que a outra pessoa deveria estar sentindo vergonha no momento (Leeming \& Boyle, 2013). A propriedade de contágio das emoções foi sublinhada por autores, principalmente no que se refere às emoções morais (Gouveia et al., 2006). 
Por fim, existe a vergonha associada à falta moral, a vergonha moral. Trata-se de reconhecer em si mesmo a responsabilidade por comportamentos que se julga imoral (Alencar \& La Taille, 2007). Por exemplo, ao trapacear em uma avaliação e mentir para os professores, um aluno que tem como valores centrais a justiça e a honestidade poderia experimentar o sentimento de vergonha por julgar a si mesmo como uma pessoa mentirosa e desonesta. A vergonha possui grande valor no campo da moralidade, já que está intimamente relacionada com a busca de representações de si com valor positivo e com o autorrespeito (ou honra), visto que a capacidade de sentir vergonha moral corresponde ao conceito moral da honra (La Taille, 2007), ou da dignidade, a saber, o autorrespeito.

Além das situações anteriormente mencionadas, há duas situações distintas no tempo, em que a vergonha é experimentada. A primeira refere-se a vergonha prospectiva, ou seja, sente-se vergonha por anteceder uma situação na qual os valores centrais da representação de si serão postos em conflito. E a segunda, refere-se a vergonha retrospectiva, desencadeada por uma situação já passada ou em curso (Harkot-de-La-Taille, 1999; La Taille, 2002a, 2002b). No primeiro caso, a vergonha prospectiva, pode funcionar como reguladora da ação, pois ao perceber que a ação futura é conflitante com seus próprios valores podese evita-la ou modifica-la. Visto que a imagem daquela situação faz o sujeito sentir vergonha, ele é assim influenciado agir de forma coerente com seus valores (La Taille, 2002a, 2002b).

Após as considerações teóricas a respeito da vergonha, é importante agora o relato de estudos empíricos sobre o tema no Brasil. Há no Brasil, até a presente data, artigos publicados por La Taille sobre a fronteira da intimidade e a vergonha e cinco estudos empíricos realizados (Araújo, 1998; Laskoski et al., 2013; La Taille, 1996; La Taille, Bedoian, \& Gimenez, 1991; La Taille, Maiorino, Storto, \& Roos 1992; La Taille, Duarte, \& Mello, 1993; Schimith, 2013). A maior parte dos estudos diz respeito à gênese do sentimento de vergonha e a fronteira moral da intimidade publicados por La Taille e seus colaboradores. Estes são seguidos da função reguladora da ação moral exercida pela vergonha, investigada por Araújo (1998) com crianças e adolescentes. Também desenvolvido com adolescentes, a pesquisa de Laskoski et al. (2013) buscaram testar a independência empírica de culpa e da vergonha para adolescentes. No mesmo ano, Shimith (2013) desenvolveu uma pesquisa com homens adultos com o objetivo foi investigar o sentimento de vergonha e sua relação com a moralidade.

Portanto, tendo em vista a importância da vergonha para o estudo da moralidade no campo da psicologia e o fato de que a maior parte dos estudos já realizados investigam sua gênese e envolvem crianças e adolescentes; o presente trabalho teve como objetivo investigar o juízo moral da vergonha em 
uma população jovem e adulta, com a intenção de conhecer a concepção dos participantes a respeito do sentimento de vergonha e investigar quais situações despertam nos participantes esse sentimento e as justificativas, a fim de contribuir com o conhecimento produzido na área.

\section{MÉTODO}

A presente pesquisa foi um estudo qualitativo e descritivo que contou com a seguinte metodologia.

\section{Participantes}

Participaram deste estudo 40 estudantes de uma universidade pública do estado do Espírito Santo, com idades entre 19 e 55 anos $(M=23,2 ; D P=6,7)$. Os universitários selecionados foram igualmente divididos quanto ao sexo e entre os que apresentaram respostas de maior e menor intensidade de vergonha em um questionário, anteriormente aplicado, que relata uma história fictícia, criada pelos pesquisadores, sobre a honra (conforme o Apêndice). Informamos ainda que os nomes utilizados para divulgação dos resultados são nomes fictícios, para poder preservar o anonimato dos participantes.

\section{Instrumentos}

Utilizou-se uma entrevista com roteiro semiestruturado realizada individualmente seguindo o método clínico piagetiano (Delval, 2002; Piaget, 1932/1994, 1926/2005). O roteiro de entrevista contém perguntas sobre a concepção de vergonha, exemplos de situações na qual os participantes sentem vergonha e a justificativa.

\section{Procedimentos}

Os estudantes convidados a participar da pesquisa foram contatados e as entrevistas marcadas em local combinado. Todos receberam o Termo de Consentimento Livre e Esclarecido que explica os objetivos da pesquisa e assegura o sigilo e anonimato dos participantes, de tal modo que serão utilizados nomes fictícios neste trabalho de acordo com os padrões éticos da Resolução No 466/2012 do Ministério da Saúde - MS (Brasil, 2012).

As entrevistas foram realizadas individualmente, gravadas na íntegra e, posteriormente, transcritas. Utilizou-se o método clínico proposto por Piaget (1932/1994, 1926/2005). O método clínico é um conjunto de procedimentos, empregado na coleta e na análise de dados, que visa investigar como pensam os participantes acerca de algum fenômeno. Ao longo da entrevista, o método clínico permite acompanhar o percurso do pensamento do participante no decorrer do protocolo de perguntas e dos possíveis casos narrados. Os dados das entrevistas foram transcritos e posteriormente realizada uma leitura minuciosa de todos os protocolos. 
A análise dos dados realizada foi qualitativa, com base na teoria piagetiana e na sistematização proposta por Delval (2002). A proposta é agrupar conteúdos de respostas semelhantes em categorias iniciais situando a resposta de cada participante em relação às categorias criadas. Para tanto, foram incialmente elaboradas as categorias detalhadas dos conteúdos de respostas de cada participante, as quais foram posteriormente reunidas em categorias resumidas de respostas gerais. Por fim foram criadas macrocategorias de análise: a primeira que reunia os conteúdos de respostas que associavam a vergonha a um controle externo, a segunda que equivalia a vergonha a um controle interno e, por fim, a que reunia conteúdos que associavam a vergonha a ambos controles.

Isto posto, serão considerados conteúdos que equivalem a vergonha a um controle externo as categorias de: conceito - juízo e/ou olhares alheios; costumes da educação, cultura e sociedade; exemplos - exposição ao olhar alheio; juízo alheio; e justificativas para os exemplos - exposição ao olhar alheio; juízo alheio; costumes da educação, cultura, sociedade.

Por sua vez, para os conteúdos que remetem à vergonha enquanto equivalente a um controle interno, serão consideradas as seguintes categorias: conceito constrangimento/desconforto/timidez; autojuízo; conteúdos próprios considerados morais; sentimento subjetivo/emocional; caráter e personalidade; sensações físicas; arrependimento; sentimento que regula a ação; exemplos comportamentos considerados imorais; contágio relacionado à ação do outro; e justificativa para os exemplos - oposição aos valores próprios considerados morais; autojuízo, fato saber o que é certo e fazer o errado; identificação com o sentimento da outra pessoa; culpa; sentimento de não fazer parte daquilo e outros ("afeto em relação ao outro"; "personalidade", "perdeu alguém importante", "perda do sentido da vida").

Por fim, os conteúdos que equivalem a vergonha tanto a um controle externo quanto controle interno são: conceito - exemplos diversos ("fazer algo errado", "não atingir as expectativas", "o contágio e a ação de fazer mal a outrem"); humilhação; exemplos - não atingir o objetivo; não saber como lidar com a situação; outros ("não concluir o curso superior"; "bater o carro"; "tomar uma atitude que os pais não esperam"; "continuar a vida depois de ter perdido um filho"); e justificativas para os exemplos - maneiras de lidar com a situação; consequências negativas do ato; humilhação e outros ("acontece, naturalmente").

\section{RESULTADOS}

Torna-se importante ressaltar que o número total de respostas ou justificativas varia a cada questão em análise, já que em algumas o participante forneceu mais de uma explanação. No que concerne à primeira questão: "o que 
você entende por vergonha?", os participantes mencionaram um total de 158 respostas agrupadas nas categorias apresentadas na Tabela 1.

Tabela 1. Categorias resumidas para as definições de vergonha.

\begin{tabular}{ccc}
\hline Categorias Resumidas & Frequência (n) & $\begin{array}{c}\text { Porcentagem } \\
(\%)\end{array}$ \\
\hline Constrangimento & 29 & 18,4 \\
Juízo e/ou olhares alheios & 27 & 17,1 \\
Exemplos diversos & 22 & 13,9 \\
Costumes da educação, cultura e & 19 & 12 \\
sociedade & 17 & 10,8 \\
Autojuízo & 16 & 10,1 \\
morais & 08 & 5 \\
Conteúdos próprios considerados & 06 & 3,7 \\
Sentimento subjetivo/emocional & & \\
Caráter e a personalidade da & 05 & 3,2 \\
pessoa & 05 & 3,2 \\
Sensações físicas & 02 & 1,3 \\
Arrependimento & 02 & 1,3 \\
Humilhação & 158 & 100 \\
\hline Total & &
\end{tabular}

Como se pode observar, a definição mais proferida pelos participantes está relacionada a Constrangimento. As respostas aqui descritas envolvem a definição de vergonha como sinônimo de constrangimento, se sentir mal em alguma situação, timidez, desconforto e se sentir acuado. Por exemplo: "Eu acho que vergonha a pessoa tem quando ela se sente desconfortável ou até mesmo acuada de certa forma em vários momentos" (Ubaldo, 24 anos).

A definição juízo e/ou olhares alheios também apareceu com bastante frequência. Assim, nessa categoria encontram-se definições de vergonha relacionadas ao juízo de terceiros e/ou ao seu olhar (exposição). Por exemplo, "quando você se coloca ali frente ao olhar do outro é... e você acha que aquele olhar a seu respeito não é positivo, é pejorativo, é recriminatório, então se manifesta um mal-estar que eu chamaria isso de vergonha" (Jurandir, 43 anos).

Em exemplos diversos, surgem respostas nas quais os participantes utilizaram exemplos de situações desencadeadoras da vergonha para defini-la. Nessa categoria, aparecem as seguintes categorias detalhadas: "fazer algo errado ou fugir do padrão", "não atingir as expectativas, uma ação de outra pessoa", "causar mal a outrem" e "agir sem pensar". No que diz respeito aos costumes da educação, cultura e sociedade, encontram-se reunidas as definições de vergonha relacionadas àquilo que a sociedade, a cultura, diz que é certo ou 
não fazer. Se a sociedade reprova algo, o sujeito vai sentir vergonha de fazer aquilo. Por exemplo, "Esse tipo de vergonha que acho que vem da cultura" (Gracinda, 19 anos) ou "algo que a sociedade vê como inaceitável" (Graziela, 20 anos).

As respostas reunidas em autojuízo dizem respeito a definições de vergonha relacionadas ao autojuízo, ao julgar-se a si mesmo e reprovar a ação. Por exemplo, "Você se fecha um pouco para pensar no que você fez (Cristina 21 anos), e "Eu acho que seria esse sentimento de reprovação, não é? (Afonso, 20 anos). As definições de vergonha relacionadas aos valores morais dos participantes aparecem em conteúdos próprios considerados morais. Relacionam-se ao que o participante acredita ser certo e errado. Por exemplo, "Uma atitude que você reprove nos seus parâmetros morais, violar seus próprios parâmetros do que é correto do que é moral (Givaldo, 20 anos).

Outro aspecto evidenciado na definição refere-se à dimensão da vergonha como uma emoção, um sentimento subjetivo. Ao contrário das sensações físicas, neste estudo, os participantes apontam para uma sensação emocional, a um sentimento de ordem involuntária, algo espontâneo que assalta o indivíduo de surpresa contra a sua vontade. Por exemplo, "é um sentimento mais emocional" (Graziela, 20 anos); "é uma coisa mais espontânea" (Gracinda, 19 anos). A vergonha também foi relacionada ao caráter e à personalidade da pessoa. Assim, dependerá da personalidade da pessoa se ela vai sentir ou não vergonha em determinada situação. Por exemplo, "eu acho que a vergonha seria alguma coisa relacionada com seu caráter" (Olga, 22 anos) e "varia muito de personalidade" (Ariana, 21 anos).

Além do aspecto subjetivo da vergonha, as respostas dos universitários destacam a relação com as sensações físicas que este desencadeia no corpo. Por exemplo, "você sente algumas reações, por exemplo, você enrubesce" (Angélica, 20 anos). O arrependimento também foi destacado como relacionado à vergonha. Sentir vergonha está associado ao sentimento de arrependimento diante de alguma situação. Por exemplo, "quando ela faz algo que às vezes ela não queria ter feito e se arrepende" (Gracinda, 19 anos) e "seria um arrependimento sobre uma própria conduta" (Givaldo, 20 anos).

As definições que relacionam a vergonha enquanto reguladora de uma possível ação, que pode inibir, impedir que alguém faça algo, foram reunidas em sentimento que regula a ação. Por exemplo, "algo que te inibe... tipo o sentimento de vergonha ele te impede de praticar alguma coisa que você faria" (Cesariano, 20 anos). Por fim, a vergonha relacionada à humilhação $(n=2)$. Por exemplo, "é um ato de você se sentir inferior ao outro" (Aurélio, 33 anos).

A seguir, serão descritos os dados encontrados a partir da segunda pergunta do instrumento: "o que faz você sentir vergonha?". As respostas dos participantes forneceram um total de 107 exemplos, que foram reunidos em sete categorias, a saber: exposição ao olhar alheio $(n=53 ; 49,6 \%)$, comportamentos 
considerados imorais $(n=27 ; 25,2 \%)$, não atingir o objetivo $(n=7 ; 6,5 \%)$, não saber como lidar com a situação $(n=6 ; 5,6 \%)$, contágio relacionado à ação do outro $(n=5 ; 4,7 \%)$, juízo alheio $(n=5 ; 4,7 \%)$ e outros $(n=4 ; 3,7 \%)$.

Em exposição ao olhar alheio foram reunidos os exemplos nos quais os participantes mencionaram que o fato de estar exposto, de ser objeto do olhar alheio, como o caso de falar em público, os faz sentir vergonha, a vergonha de exposição. Portanto, surge menção nesta categoria de exemplos que remetem à exposição pura e simples ao olhar alheio (a um público qualquer, ou a alguém desconhecido). Por exemplo, "quando eu estou em público com muita gente que eu não conheço" (Verônica, 22 anos).

Os participantes mencionaram que sentem vergonha quando apresentam comportamentos considerados imorais, ou seja, tudo aquilo que contraria a sua moral e os seus valores. Nesta categoria há respostas como: roubar, reagir ou agir de modo agressivo, ofender alguém - humilhar, mentir, colar na prova e saber o que é certo e fazer o errado. Por exemplo, "tudo aquilo que me diminuiria aos meus próprios olhos" (Jurandir, 43 anos); "quando eu sei o que é certo e errado e fizer o errado" (Graciano, 19 anos); "Colar em uma prova" (Antônia, 55 anos); "mentir" (Vando, 20 anos); e "me apropriar daquilo que não é meu" (Gardênia, 21 anos).

Outro exemplo de situação desencadeadora da vergonha é não atingir os objetivos. Os participantes mencionaram sentir vergonha quando falham, fracassam em algo, ou não atingem os seus objetivos. Por exemplo, "não conseguir fazer algo que eu me propus a fazer" (Vanderlei, 26 anos) e "fraquejar diante de uma situação em que eu tenho uma opção e não faço uma opção correta" (Jurandir, 43 anos). Quanto a não saber como lidar com a situação, surgiram exemplos em que os participantes mencionaram que sentem vergonha quando estão em uma situação inesperada, não sabem como lidar com aquilo, e quando não se sentem preparados para fazer algo. Por exemplo, "situações inusitadas que a gente não sabe como reagir que sai do campo do que é comum" (Valéria, 25 anos).

O contágio relacionado à ação do outro foi um dos exemplos citados. Foi mencionado pelos participantes que sentem vergonha por outras pessoas ou por causa de coisas que outras pessoas fazem ou fizeram. Por exemplo, "tenho vergonha de algumas coisas que meu irmão faz" (Afonso, 20 anos) e "sinto vergonha quando alguém não dá preferência para um idoso, para um cadeirante, qualquer pessoa que tenha uma restrição" (Helena, 24 anos).

Por sua vez, em juízo alheio estão contidos exemplos nos quais eles mencionam sentir vergonha por causa do juízo alheio, da crítica do outro, ao fato de se preocupar com o pensamento e o juízo alheio. Por exemplo, "medo das pessoas me julgarem mal" (Graciano, 19 anos) e "eu fico envergonhada com o que as pessoas vão pensar sobre mim" (Ariana, 21 anos). Por fim, em outros (7) encontram-se os exemplos que não se adequam em nenhumas das categorias 
anteriores, como não se sentir incluído em algum contexto, contrariar os pais, dentre outros. Por exemplo, "é em relação aos meus pais, de eu tomar uma atitude que eles não esperam" (Arlindo, 22 anos).

No que se refere ao juízo moral sobre o conceito de vergonha, serão expostas as justificativas para cada exemplo citado pelos participantes. Ou seja, "por que sentem vergonha em determinada situação"? Foram obtidos um total de 177 justificativas, distribuídas nas seguintes categorias: Juízo alheio $(n=47$; $26,6 \%)$; Maneiras de lidar com a situação ( $n=30 ; 16,9 \%)$; Exposição ao olhar alheio $(\mathrm{n}=26 ; 14,7 \%) ;$ Oposição aos valores próprios considerados morais $(\mathrm{n}=24 ; 13,6 \%)$; Costumes da educação, cultura, sociedade, religião $(\mathrm{n}=14$; $7,9 \%) ;$ Autojuízo $(\mathrm{n}=7 ; 4,0 \%)$; Saber o que é certo e fazer o errado $(\mathrm{n}=5$; $2,8 \%)$; Identificação com o sentimento da outra pessoa ( $\mathrm{n}=05 ; 2,8 \%)$; Consequências negativas do ato $(n=4 ; 2,2 \%)$; Culpa $(n=3 ; 1,7 \%)$; Humilhação $(n=3 ; 1,7 \%)$; Sentimento de não pertencer à situação $(n=3 ; 1,7 \%)$; Dado perdido $(n=1 ; 0,6 \%)$; Outros $(n=5 ; 2,8 \%)$.

A categoria de maior frequência, juízo alheio, compreende as falas nas quais os participantes se remetem aos juízos alheios como justificativa para a vergonha, ou seja, sentem vergonha por que se preocupam em que pensamento ou crítica o outro terá sobre ele. Por exemplo, "é mais a expectativa, eu acho, do que as pessoas vão achar do que eu estou falando na hora" (Ubaldo, 24 anos).

Em as maneiras de lidar com a situação estão as sentenças nas quais os participantes se remetem à forma como lidam com o exemplo por eles citados como o motivo para vergonha. Esta categoria identifica as formas de enfrentamento que apontam para o desconforto causado pela situação; o fato de estar fazendo algo que não queria; o medo de errar; o fato de não saber se comportar diante do ocorrido; e o fato de não se sentir capacitado e/ou preparado diante de algo. Como nos exemplos: "um desconforto assim, que causa uma certa vergonha" (Celso, 25 anos); "às vezes você não quis estar naquela situação, você é obrigado a estar naquela situação" (Ariana, 21 anos); "medo de errar (Graciano, 19 anos); "eu fico sem saber como me comportar" (Graça, 22 anos); "Você vê os outros fazendo e você tem uma limitação e não consegue corresponder" (Davi, 20 anos); "me sentindo meio incapaz ou meio impotente" (Aurélio, 33 anos); e "porque você deveria estar preparada para aquilo, ou pelo menos se preparar para aquilo ali" (Antônia, 55 anos).

A exposição ao olhar alheio é o argumento utilizado pelos participantes referente aos olhares alheios para justificar a vergonha, ou seja, eles sentem vergonha por causa do olhar alheio. A simples exposição desencadeia a vergonha, bem como a presença de pessoas desconhecidas, que intimidam o participante. Por exemplo, "porque tem várias pessoas vendo" (Ubaldo, 24 anos) e "porque isso te expõe" (Vando, 20 anos).

Reunidas em oposição aos valores próprios considerados morais encontram-se as justificativas relacionadas aos valores que os participantes 
consideram como morais, ou seja, sentem vergonha por causa de seus valores morais, seus princípios, pois o ato em questão está em oposição aos seus valores. Por exemplo, "porque vai contra o meu... a minha moral, aquilo que eu constituo como a minha própria moral" (Olga, 22 anos); "Às vezes eu acho assim que uma disputa desleal, assim sabe, não é uma coisa muito ligada a com ser justo" (Vanderlei, 26 anos) e "porque toda pessoa merece respeito" (Graciano, 19 anos).

Por sua vez, costumes da educação, cultura, sociedade remetem aos costumes passados pela educação familiar, pela cultura, pela sociedade e pela religião como motivação para a vergonha, ou seja, sentem vergonha porque a educação recebida, a cultura, a sociedade e a religião ensinam que deve se sentir vergonha. Por exemplo, "não, você não deve, é uma regra familiar, não pode fazer isso" (Edmundo, 20 anos); "então, é uma pressão social" (Gardênia, 21 anos); "acho que baseado na percepção que eu tenho porque eu sou cristão" (Evandro, 20 anos) e "acho que a cultura traz muito isso" (Gracinda, 19 anos).

O autojuízo foi apresentado como justificativa. Nesse aspecto, os participantes explicam a vergonha decorrente de uma situação devido ao autojuízo, ou seja, por julgar-se a si mesmo e reprovar a ação. Por exemplo, "é um 'subjugamento' meu mesmo, aí eu fico meio mal por isso assim" (Aurélio, 33 anos) e "eu fiquei com vergonha por perceber a minha ignorância" (Guilhermina, 21 anos). Os participantes também argumentam que o fato de saber o que é certo e errado e fazer o errado é razão para sentir vergonha. Por exemplo, "você sabe que aquilo não está certo que não estudar está errado" (Germana, 20 anos).

Quanto às explicações que ressaltam a identificação com o sentimento da outra pessoa foram reunidas nesta categoria as falas dos participantes que remetem à identificação com a outra pessoa, ou seja, no lugar dela o participante sentiria a mesma coisa. Por exemplo, "se eu me colocasse no lugar do outro, talvez eu ficaria magoada; aí eu vejo que ele está se sentindo assim" (Graciela, 20 anos).

Em consequências negativas do ato as argumentações reunidas fazem menção às consequências que são desencadeadas com o exemplo como motivo para sentir vergonha. Por exemplo, "medo de ter uma consequência pior" (Graciela, 20 anos) e, "mas eu acho que mais ou menos tem aquele medo da represália" (Afonso, 20 anos). Por sua vez, a culpa, os argumentos apresentados pelos participantes remetem ao sentimento de culpa resultante da situação. Por exemplo, "vou sentir culpa" (Gael, 27 anos) e "a mentira por si só já traz muita carga de culpa de consciência pesada, de mal-estar pelo menos para mim" (Vando, 20 anos).

Outro sentimento apresentado foi a humilhação, principalmente quando eles se referem ao fato de se sentirem inferiores e humilhados como razão da vergonha. Por exemplo, "me sinto inferior em relação a isso" (Germana, 20 
anos) e "um sentimento que gera vergonha, acho que é realmente eu me sentir menor que o outro assim, sabe" (Aurélio, 33 anos).

Nos argumentos reunidos em sentimento de não pertencer à situação, a vergonha é desencadeada porque o indivíduo sente que não pertence à situação ou ao lugar. Sentem-se deslocados, como se não pertencessem àquele lugar ou situação, como na fala a seguir, "e de não conseguir acompanhar por não fazer parte daquilo, você se perder, não acompanhar, ou travar mesmo. Meio que medo de tentar e estar como intruso" (Germano, 21 anos). Por fim, há um dado perdido. Apesar da utilização do método clínico, um participante não conseguiu justificar um dos exemplos por ele citado, sendo a resposta considerada um dado perdido.

\section{DISCUSSÃO}

O presente trabalho foi um estudo exploratório que buscou analisar como os estudantes universitários compreendem o sentimento de vergonha e quais situações são mencionadas por eles como eliciadoras desse sentimento, bem como as justificativas apresentadas por eles. Por meio dos resultados encontrados, é possível inferir a existência de uma variedade de definições, exemplos e justificativas para a vergonha. Isso possibilita analisar o juízo moral dos participantes a respeito desse sentimento.

A análise será feita primeiramente explicando-se as categorias mais frequentes cujos conteúdo dos juízos equivalem a um controle externo. Em seguida, serão analisados os conteúdos que remetem à vergonha enquanto equivalente a um controle interno. Finalmente, os conteúdos que remetem a ambos os controles.

É importante salientar que as macrocategorias definidoras da vergonha enquanto equivalentes a controle interno e/ou externo não se tornam definições estanques, mas, ao contrário, especificam predominâncias entre as quais ocorre que a vergonha pode agir ora como controle interno e ora como controle externo e, em alguns casos, como ambos. Ressaltamos também que não haverá discussão de todos os conteúdos das macrocategorias, apenas os que apareceram em maior frequência e/ou com relevância teórica para o presente estudo. No entanto, será apresentada a porcentagem total para cada macrocategoria de análise.

Ao todo, 43,2\% ( $n=191)$ das respostas e justificativas relacionam-se juízo da vergonha enquanto equivalente a um controle externo, sendo que o conteúdo mais associado à vergonha pelos participantes foi o de juízo alheio e o de exposição a olhares alheios. As categorias de exposição e o juízo alheio aparecem associadas ao conceito de vergonha, bem como nos exemplos e justificativas apresentados para eles. Assim, na definição, juízo e exposição aos olhares, foram reunidos na mesma categoria por terem sido mencionados como 
conteúdos interligados, e nos exemplos e justificativas foram reunidos em categorias separadas.

Esses dados confirmam que o simples fato de ser olhado desperta vergonha, ao se perceber objeto e causa de julgamento para o outro. De igual modo, outros estudos apresentam a associação do sentimento de vergonha à exposição (Leeming \& Boyle, 2013; Schimith, 2013), e a preocupação com o juízo de terceiros sobre suas ações (Tangney \& Miller, 1996). Dessa forma, nem sempre o olhar alheio aparece acompanhado do juízo, mas, como visto na literatura, ocupar esse lugar de ser objeto para o outro é a principal justificativa para sentir vergonha, pois, na vergonha, o lugar do outro é o de juiz, é o olhar do outro que, inicialmente, instaura a vergonha (Araújo, 2001; Harkot-De-LaTaille, 1999; La Taille, 2002a, 2002b).

Para os conteúdos de controle interno, 38,7\% $(n=171)$ das respostas e justificativas encontradas se encaixam nesta macrocategoria. O primeiro a ser analisado refere-se ao juízo de vergonha que envolve os conteúdos próprios considerados morais, mencionado na definição; os comportamentos considerados imorais, citado como exemplo desencadeador de vergonha; e a oposição aos valores considerados morais, conteúdo mencionado na justificativa dos exemplos.

A vergonha pode estar ligada a diferentes valores, amorais, imorais e morais (La Taille, 2001, 2006), ou seja, o indivíduo sentirá vergonha quando romper com padrões, dentre eles padrões morais. Uma vez que a vergonha incide sobre o eu, e este é um conjunto de representações de si com valor positivo (Tognetta \& La Taille, 2008), o sujeito vai sentir vergonha toda vez que agir contra seus princípios. No caso de conteúdos morais, o sujeito sentirá vergonha quando agir de forma contrária a valores morais que ele possui como centrais, caracterizando-se em uma perda de valor.

De igual modo, conteúdos que associam a vergonha ao caráter e à personalidade das pessoas foram mencionados tanto nas definições, quanto nas justificativas dos exemplos. Segundo La Taille (2010), para que uma pessoa seja feliz, ela necessariamente precisa se julgar uma pessoa de valor (La Taille, 2010). Isso só é possível quando as atitudes da pessoa são condizentes com a "boa imagem" que ela tem de si mesma. Por outro lado, quando o sujeito não mantém essa coerência entre as atitudes e a "boa imagem", pode surgir o sentimento de vergonha. Dessa forma, "trata-se do sentimento de perda de valor pessoal" (La Taille, 2009, p. 14). As respostas anteriormente mencionadas definem a vergonha por meio da perda de valores, que podem ser morais ou não. Os respondentes priorizam certas condutas, que constituem a "boa imagem" que possuem de si e, no caso de incoerência com esta, surge a vergonha.

O autojuízo foi mencionado pelos participantes tanto na definição de vergonha quanto na justificativa para os exemplos citados. De fato, La Taille 
(2002a, 2002b) sublinha o fato de que o juízo alheio só desencadeia a vergonha se o sujeito tomar este juízo para si, ou seja, pressupõe um autojuízo negativo, visto que a vergonha se constitui por eventos que inserem o sujeito no centro da sua consciência, ou seja, faz com que ele realize uma autoavaliação de seu self.

Outra característica, também mencionada pelos participantes na definição é a de que a vergonha é um sentimento que regula a ação (La Taille, 2002a, 2002b). Ao perceber que a ação é conflitante com seus próprios valores, o sujeito é assim influenciado a julgar e fazer as suas ações de modo a corresponder a seus valores. E, uma vez que diante de uma exposição virtual, pode ser desencadeada uma vergonha prospectiva, esta pode agir de modo a mudar a ação do sujeito, devido ao desconforto de se imaginar naquela situação. A vergonha age regulando a ação antes de ela acontecer. Entretanto, ressalta-se que no presente estudo foi investigado o juízo moral dos estudantes acerca do sentimento, e não a ação diante do mesmo. Assim configura-se um estudo acerca do juízo do sentimento e não do sentimento em si. Portanto, não podemos averiguar se e o conteúdo de resposta sobre o papel regulador da ação, seria aplicado também as ações do sujeito.

Uma das justificativas apresentada para os exemplos de situações desencadeadoras da vergonha é a culpa. A culpa e a vergonha têm sido temas de estudos no campo da Psicologia e estes apontam que, embora sejam construtos diferentes, essas emoções podem ser vividas de forma associada em algumas situações (La Taille, 2002a, 2002b). Pode-se considerar, então, o seguinte processo: a ação desencadeia a culpa; ao sentir culpa, o sujeito julga a ação como incorreta e, por conseguinte, julga a si mesmo como incorreto por praticar essa ação, desencadeando a vergonha.

Na sequência, em análise às respostas que demarcam o juízo da vergonha ligado ao constrangimento, cujo conteúdo foi o mais citado na definição desse sentimento, algo importante de se destacar, uma vez que o constrangimento é demarcado por diversos estudos como um construto diferente da vergonha (Gouveia, et al., 2005; Gouveia, et al., 2006; Sabini, et al., 2001). Embora teoricamente definidos como distintos, observou-se que o constrangimento foi utilizado pelos participantes com bastante frequência para definir a vergonha. Tal ocorrência pode ser explicada pela característica que ambos, vergonha e constrangimento, possuem em comum, a saber: o desconforto psíquico, o não se sentir bem diante de determinada situação (La Taille, 2002a, 2002b).

No que diz respeito aos conteúdos de respostas que associam a vergonha às sensações físicas, esses demarcam a experiência emocional da vergonha e suas reações desencadeadas no corpo, como rubor, frio na barriga, suor. $\mathrm{Na}$ experiência de vergonha, o indivíduo apresenta algumas respostas psicofisiológicas em consequência de um estado de inadequação e elas expressam o mal-estar que a pessoa sente (Darwin, 1872/1981; Pitt-Rivers, 1965; Tangney \& Miller, 1996). Darwin (1872/1981) evidencia o fato de o rubor 
nas faces constituir a experiência mais específica do ser humano, pois aparece quando alguém se torna ciente do próprio corpo, ou seja, uma experiência no qual o ego é colocado em evidência, logo, se trata da vergonha.

Tendo exposto os conteúdos de controle externo e interno separadamente, surgem aqueles que associam a vergonha tanto a um controle externo quanto interno, que correspondem a $17,9 \%(n=79)$ dos dados encontrados. Houve definições que recorreram a exemplos diversos de situações que desencadeiam a vergonha para esclarecer o sentimento. Algumas dessas definições também apareceram quando se solicitou aos participantes que citassem especificamente exemplos de situações que os fazem sentir vergonha.

$\mathrm{Na}$ definição de vergonha, dentro da categoria exemplos diversos, tem-se a categoria detalhada "não atingir as expectativas". De fato, a vergonha também aparece junto à experiência de fracasso e incapacidade como ressaltam alguns autores (Alencar \& La Taille, 2007; La Taille, 2002b; Tangney \& Miller, 1996). Os dados do presente estudo mostram que as situações nas quais não se atinge as expectativas, isto é, vive-se o fracasso ou falha em algo, desencadeiam no sujeito a vergonha associada a sentimentos de desvalorização.

Outra microcategoria que apareceu na definição de vergonha, dentro de exemplos diversos, envolve os juízos que associam o sentimento à "ação de causar mal a outrem". Os autores Leeming e Boyle (2013) encontraram em seu estudo registro a essa ação na descrição dos participantes de episódios em que sentiram vergonha. Os dados do presente estudo confirmam que a vergonha também está associada a situações nas quais o sujeito causa danos a terceiros, ou seja, essa ação faz com que a pessoa julgue a si mesmo como desonrada.

Outro conteúdo que surgiu tanto na definição como nos exemplos de vergonha foram os juízos que a associam a uma ação de outra pessoa, ou seja, contágio relacionado à ação do outro. A vergonha ocorre não devido a uma atitude ou situação na qual o sujeito está em foco, mas devido a uma ação ou situação em que outro é o protagonista e que, ainda assim, origina o sentimento no sujeito como consequência de uma identificação ou até mesmo empatia. Pode-se afirmar que o sujeito reproduz o sentimento que ele julga que o outro está sentindo, ou pelo menos deveria sentir. De fato, as pessoas possuem a propensão a "imitar", fenômeno que acontece de forma inconsciente, as expressões emocionais do outro, o que resulta em uma experiência emocional simultânea e congruente com a original (Gouveia et al., 2006). Isso também ocorre com a vergonha de contágio (Harkot-De-La-Taille, 1999; La Taille, 2002b).

Por fim, apresentaremos a análise do conceito e das justificativas para os exemplos que associam a vergonha a humilhação. A relação entre esses dois sentimentos justifica-se uma vez que em ambos acontece um rebaixamento do self. O sujeito sente-se inferiorizado, afinal, o que está em jogo é uma perda de valor. Muitas vezes, a vergonha pode ser resultado de uma situação de 
humilhação, ou pode surgir associada a esta em uma situação em que há um ataque à 'boa imagem' do sujeito (Alencar \& La Taille, 2007; Harkot-De-LaTaille, 1999; La Taille, 2002a, 2002b, 2006). Quando convidados a definir a vergonha, bem como quando solicitados a explicar os exemplos por eles citados, os estudantes trazem a humilhação associada à vergonha. Contudo, não foi possível verificar a diferença entre vergonha e humilhação para os participantes, visto que não era esse o objetivo deste estudo. A vergonha é apontada, em alguns casos, como decorrente de uma situação de humilhação (La Taille, 2002a, 2002b), nesse sentido a vergonha relaciona-se à perda de valor, isto é, a pessoa se sente envergonhada por estar rebaixada e desvalorizada. Isso explicaria a associação da vergonha à humilhação por parte dos participantes.

Dados os resultados aqui expostos, pode-se inferir que o juízo de valor moral dos estudantes sobre a vergonha compreende esse sentimento como correspondente a um controle externo e a um controle interno, visto que não houve diferenças percentuais muito relevantes entre as duas macrocategorias. Como ressaltado anteriormente, as macrocategorias utilizadas para esta análise não são estanques, mas, antes, apresentam predominâncias de tipos de controle exercidos pela vergonha, entre os quais ocorre uma dialética, uma vez que a vergonha pode agir ora como controle interno ora como controle externo e, em alguns casos, como ambos.

\section{CONSIDERAÇÕES FINAIS}

De modo geral, a proposta do presente estudo foi investigar os juízos de valor moral de estudantes universitários em relação ao sentimento de vergonha. Para tanto, pesquisou-se o conceito de vergonha, os exemplos espontâneos associados a ela e suas respectivas justificativas. Os dados mostram que o juízo de valor moral da vergonha envolve conteúdos que a definem correspondentemente a um controle externo e a um controle interno, sendo as categorias mais citadas juízo e/ou olhares alheios e autojuízo, respectivamente. Observou-se, então, que os juízos apresentados pelos participantes compreendem a vergonha tanto como um controle externo, quanto interno, referentes à sua definição, com diferenças percentuais pequenas entre as duas macrocategorias.

De fato, a vergonha associada à exposição e ao juízo alheio decorre da vergonha equivalente a um controle externo. Entretanto, é possível que o sujeito sinta vergonha sozinho, ou antes mesmo de fazer algo. Logo, a exposição e o juízo estão interiorizados pelo sujeito, tratando-se, assim, não da predominância do controle exclusivamente externo, mas também da vergonha como um controle interno. La Taille (2002b) pontua que o juízo alheio só desencadeia a vergonha se for legitimado pelo sujeito, ou seja, pressupõe um autojuízo. Logo, a vergonha incide não só sobre o parecer, mas sobre o ser (La Taille, 2002b). 
Assim, é um sentimento no qual estão em foco os valores das representações de si, em como o sujeito vê a si mesmo e como ele gostaria de ser reconhecido pelos outros. Configura-se, então, como um sentimento moral importante, que pode desempenhar um papel relevante na regulação da ação e nos juízos morais. Desse modo, na vergonha, a "boa imagem" que a pessoa tem de si mesma é abalada. Isto é, surge um sentimento de perda de valor pessoal ou perda do autorrespeito, a saber, a própria honra (La Taille, 2002b, 2009).

No que concerne às limitações do presente estudo, ressaltamos que o objetivo foi investigar o juízo moral dos estudantes acerca do sentimento e não a ação diante do mesmo. Portanto, trata-se do juízo de valor moral do sentimento e não do sentimento em si. De tal forma, sugerimos que novos trabalhos sejam realizados de maneira que se possa investigar a relação do juízo moral do sentimento e da representação da ação do mesmo.

Em suma, pretende-se que os resultados emanados desta pesquisa sejam esclarecedores para a comunidade científica, os profissionais de um modo geral, e os demais interessados no tema. Almeja-se subsidiar e promover a realização de outros estudos dedicados a investigar a influência da afetividade na moralidade. E se espera, também, que a presente pesquisa possa fornecer subsídios para propostas de intervenção e educação em valores morais que visem as virtudes como centrais para a construção de personalidades éticas.

\section{REFERÊNCIAS}

Alencar, H. M. (2003). Parcialidade e imparcialidade no juízo moral: a gênese da participação em situações de humilhação pública. (Tese de doutorado não publicada). Universidade de São Paulo, São Paulo.

Alencar, H. M., \& La Taille, Y. (2007). Humilhação: o desrespeito no rebaixamento moral. Arquivos Brasileiros de Psicologia, Rio de Janeiro, 59(2), 217-231. doi: 10.1590/S1413-85572010000200009

Anolli, L. (2003). A vergonha: quando nossa autoimagem faz-se em pedaços e o que mais queremos é desaparecer. São Paulo, SP: Paulinas.

Anolli, L., \& Pascucci, P. (2005). Guilt and guilt-proneness, shame and shameproneness in Indian and Italian young adults. Personality and Individual Differences, 39(5), 763-773. doi: 10.1177/0022022108321178

Araújo, U. F. (1998). O sentimento de vergonha como um regulador moral. (Tese de doutorado não publicada). Universidade de São Paulo, São Paulo.

Araújo, U. F. (2001). Ética docente: vergonha e humilhação. Revista Profissão Docente, Uberaba, 1(1), 1-13.

Brasil (2012). Resolução 466/2012 do Ministério da Saúde. Diretrizes e normas regulamentadoras de pesquisas envolvendo seres humanos. Brasília: Ministério da Saúde. 
Costa, C. F. C. D. (2008). As emoções morais: vergonha e culpa, e as bases motivacionais do ser humano. (Dissertação de mestrado não publicada). Universidade de Lisboa, Lisboa.

Darwin, C. (1981). A expressão das emoções no homem e nos animais (L. S. L. Garcia, Trad.). São Paulo: Companhia das letras. (Original publicado em 1872).

Delval, J. (2002). Introdução à prática do método clínico: descobrindo o pensamento das crianças. (F. Murad, Trad.). Porto Alegre: Artmed.

Gouveia, V. V., Singelis, T. M., Guerra, V. M., Santos, W. S., \& Vasconcelos, T. C. (2005). Auto-imagem e sentimento de constrangimento. PSICO, Porto Alegre, PUCRS, 36(3), 231-241.

Gouveia, V. V., Singelis, T. M., Guerra, V. M., Santos, W. S., Rivera, G. A., \& Vasconcelos, T. C. (2006). O sentimento de constrangimento: evidências acerca do contágio emocional e do gênero. Estudos de Psicologia, Campinas, 23(4), 329-337. doi: 10.1590/S0103-166X2006000400002

Harkot-De-La-Taille, E. (1999). Ensaio semiótico sobre a vergonha. São Paulo: Humanitas/FFLCH/USP.

Laskoski, L. M., Natividade, J. C., \& Hutz, C. S. (2013). Development of Instruments to Assess Shame and Guilt in Adolescents: Empirical Differences Between the Constructs. Paidéia, Ribeirão Preto, 23(55), 171-178. doi: 10.1590/1982-43272355201304

La Taille, Y. (1996). Os conceitos de humilhação e honra em crianças de 7 e 12 anos de idade. In Z. A. Trindade, \& C. Camino (Eds.). Cognição social e juízo moral. (vol. 1, pp. 137-154). Rio de Janeiro: Associação Nacional de Pesquisa e Pós-graduação em Psicologia (ANPEPP).

La Taille, Y. (2001). A questão da indisciplina: ética, virtudes e educação. In: Demo, P., La Taille, Y., \& Hoffmann J. (Eds.), Grandes pensadores em educação: o desafio da aprendizagem, da formação moral e da avaliação (pp. 67-98). Porto Alegre: Mediação.

La Taille, Y. (2002a). O Sentimento de Vergonha e suas Relações com a Moralidade. Psicologia: Reflexão e Crítica, Porto Alegre 15(1), 13-25. doi: 10.1590/S0102-79722002000100003

La Taille, Y. (2002b). Vergonha: a ferida moral. Petrópolis: Vozes.

La Taille, Y. (2006). Moral e ética: dimensões intelectuais e afetivas. Porto Alegre: Artmed.

La Taille, Y. (2007). Desenvolvimento Humano: contribuições da Psicologia Moral. Psicologia USP, São Paulo, 18(1), 11-36. doi: 10.1590/S010365642007000100002

La Taille, Y. (2009). Construção da consciência moral. Prima Facie revista de ética, Portugal, 2, 7-30.

La Taille, Y. (2010). Moral e Ética: Uma Leitura Psicológica. Psicologia: Teoria e Pesquisa, 26(num. Esp.), 105-114. doi: 10.1590/S0102-37722010000500009 
La Taille, Y., Bedoian, G., \& Gimenez, P. A. (1991). A construção da fronteira moral da intimidade: o lugar da confissão na hierarquia de valores morais em sujeitos de 6 a 14 anos. Psicologia, Teoria e Pesquisa, Brasília, 7(2), 91-110.

La Taille, Y., Maiorino, C., Storto, D.N., \& Roos, L.C.P.V. (1992). Construção da fronteira moral da intimidade: a humilhação e a vergonha na educação moral. Cadernos de Pesquisa, São Paulo, (82), 43-45.

La Taille, Y., Duarte, C.S., \& Mello, P.C. (1993). A fronteira moral da intimidade: desenvolvimento moral e construção de normas que regulam o falar-de-si. Psicologia, Teoria e Pesquisa, Brasília, 9(1), 51-73.

Leeming, D., \& Boyle, M. (2013). Managing shame: An interpersonal perspective. British Journal of Social Psychology, 52(1), 140-160. doi: 10.1111/j.20448309.2011.02061.x

Orth, U., Robins, R. W., \& Soto, C. J. (2010). Tracking the trajectory of shame, guilt, and pride across the life span. Journal of Personality and Social Psychology, 99(6), 1061-1071. doi: 10.1037/a0021342

Piaget, J. (1994). O juízo moral na criança. Tradução de E. Leonardon. São Paulo: Summus. (Trabalho original publicado em 1932).

Piaget, J. (2005). Introdução - Problemas e Métodos. In $A$ representação do mundo na criança (pp. 9-31). (A. U. Sobral, Trad.). Aparecida, SP: Idéias e Letras (Trabalho original publicado em 1926).

Pitt-Rivers, J. (1965 -s.d). Honra e posição social. In J. G. Peristiany (Ed.). Honra e vergonha: valores das sociedades mediterrânicas (pp. 11-55). (J. C. Lisboa, Trad). Lisboa, Fundação Calouste Gulbenkian.

Sabini, J., Garvey, B., \& Hall, A. L. (2001). Shame and Embarrassment Revisited. Personality and Social Psychology Bulletin, 27(1), 104-117. doi: 10.1177/0146167201271009

Santos, A. S. (2009). Diferenças individuais na tendência para a vergonha e culpa: Antecedentes motivacionais. (Dissertação de mestrado não publicada). Universidade de Lisboa, Lisboa, Portugal.

Schimith, P. B. (2013). Psicologia da moralidade e psicanálise: um estudo sobre a vergonha. (Dissertação de Mestrado não publicada). Universidade Federal do Espírito Santo, Espírito Santo.

Stoeber, J., Harris, R. A., \& Moon, P. S. (2007). Perfectionism and the experience of pride, shame, and guilt: Comparing healthy perfectionists, unhealthy perfectionists, and nonperfectionists. Personality and Individual Differences, 43(1), 131-141. doi:10.1016/j.paid.2006.11.012

Tangney, J. P., \& Miller, R. S. (1996). Are shame, guilt, embarrassment distinct emotions? Journal of Personality and Social Psychology, 70(6), 1256-1269. doi: 10.1037/0022-3514.70.6.1256

Tangney, J. P., Stuewing, J., \& Mashek, D. J. (2007). Moral emotions and moral behavior. Annual Review of Psychology, 58, 345-372. doi: 10.114/annurev.psych.56.091103.070145 
Tangney, J. P., \& Tracy, J. L. (2012). Self-conscious emotions. In M. Leary, \& J. P. Tangney (Eds.), Handbook of self and identity (2a Ed., pp. 446-478). New York, NY: Guilford.

Tognetta, L. R. P., \& La Taille, Y. (2008). A Formação de Personalidades Éticas: Representações de Si e Moral. Psicologia: Teoria e Pesquisa, Brasília, 24(2),181-188. doi: 10.1590/S0102-37722008000200007

Tracy, J. L., \& Robins, R. W. (2006). Appraisal antecedents of shame and guilt support for a Theoretical Model. Personality and Social Psychology Bulletin, 32(10), 1339-1351. doi: 10.1177/0146167206290212

\section{Apêndice}

Instrumento utilizado para selecionar os participantes da pesquisa.

HISTÓRIA: (versão feminina: Marcela)

"O professor faz uma pergunta para Marcelo, mas não considera a resposta satisfatória. O professor, então, diz que Marcelo é burro e que não tem futuro. Marcelo agride o professor com um soco. "

O que Marcelo deveria sentir depois de ter agredido o professor com um soco?

( )nenhuma vergonha ( )pouca vergonha ( )vergonha ( )muita vergonha ( ) extrema vergonha

Recebido em: 20/01/2016

1 a revisão em: $14 / 03 / 2016$

$2^{a}$ revisão em: 28/03/2016

Aceito em: 04/04/2016

Mayara Gama de Lima é psicóloga e mestre em Psicologia pelo Programa de Pósgraduação em Psicologia da Universidade Federal do Espírito Santo. mayaragl@gmail.com.

Heloisa Moulin de Alencar é Professora Associada IV da Universidade Federal do Espírito Santo, líder do diretório do CNPq denominado "Psicologia da Moralidade: processos de desenvolvimento e contextos socioculturais" e Coordenadora do Laboratório de Psicologia da Moralidade (LAPSIM). heloisamoulin@gmail.com 